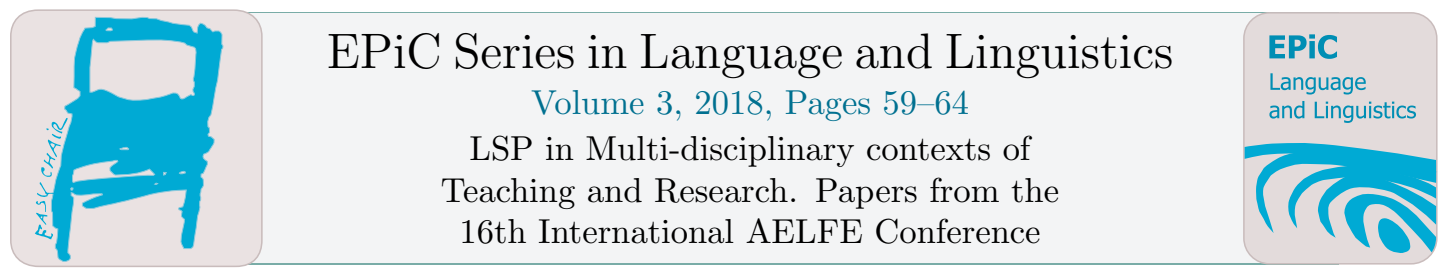

\title{
Academic writing for Spanish scholars: exploring the challenges with argumentation analysis
}

\author{
Samira Allani \\ Department of Applied Linguistics, Universidad Politécnica de Madrid, (Spain); Email: samira.allani@upm.es
}

\begin{abstract}
The present study focuses on the academic discourse shaped by Spanish scholars publishing in English. Writing and publishing in the academia are regarded as central not only to the construction of knowledge in individual disciplines but also to the construction of the identities of scholars and the negotiation of their positions and voices within academic communities (Hyland 2013). Drawing upon the theoretical stances of argumentation theory and more particularly on Pragma-dialectics (van Eemeren \& Grootendorst, 2004), the aim of this study is to explore the discursive practices of the Spanish scholars who engage in the academic "debates" of their respective communities using English as a second language. While the need for participation in English is increasing around the world, the experience of publishing in a second language has been widely identified as challenging (Hanauer \& Englander, 2010; Moreno et al., 2012). The study uses the systematic method of Pragma-dialectics to examine sixty research articles from scientific and engineering disciplines and to determine how their authors discursively construct their work and how they make a case for their contributions. The analysis focuses on the authors' strategic maneuvering, which is the efforts arguers make in argumentative discourse to reconcile aiming for rhetorical effectiveness with maintaining dialectical standards of reasonableness (van Eemeren, 2010). Argumentative strategies highly underlie the reasoning patterns of individuals (Mercier \& Sperber, 2011) and the way they position themselves and their claims within a given communicative situation. The systematic analysis of argumentative strategies attempts to shed some light on the writing practices of Spanish scholars and the stances they maintain within more and more demanding academic environments.
\end{abstract}

Keywords: academic writing; argumentation: strategic maneuvering; reasoning

\section{Introduction}

English has long been recognized as the language of science and research. Publishing in English has become essential for scholars from all academic disciplines. It increases the visibility of their work and enables them to be recognized among their academic community. The current study aims to explore the challenges experienced by non-native English-speaking scholars publishing their research reports in international English language journals. 
The study focuses on Spanish scholars and their strategies. Drawing on argumentation theory, it examines the argumentative strategies they use to convince their audience of the usefulness of their work within the limited space of an abstract. Being seemingly aimed at summarizing a piece of research, abstracts disguise their argumentative essence behind their formalism and the higher purpose of constructing scientific knowledge. Indeed, abstracts are the place scholars use to engage with their discourse communities and to invite them to reflect, accept or react to their research proposals. Their argumentative skills are fundamental, as they are expected to demonstrate "absolute truth, empirical evidence or flawless logic" (Hyland, 2004: 193). The argumentative strategies scholars use to convince the journal referees of the expediency of their research work highly reflect the way they position themselves among their wider scientific community.

\section{Academic writing in scientific disciplines}

Academic writing and the wide variety of academic text types have been the focus of attention of various research disciplines, mainly genre analysis (Swales, 1990; Bhatia, 2014), which have developed heuristic approaches in order to determine the structural and/or functional characteristics of these discourse types to serve instructional purposes. Academic writing has a range of distinguishing features which vary from a discourse community to another. Indeed, writing as a communicative act in the community is part of wider social practices of the scholarly institutions and their cultures (Hofmann, 2014). Based on this assumption, researchers show more and more interest in dimensions that go beyond the textual level and seek to explore how scholars use writing in the construction of their scientific knowledge. Along with a number of writing research experts (Flowerdew, 2013; Hanauer \& Englander, 2011), Hyland studies academic writing in light of the emergence of English as the language of science and focuses on the burdened academics around the world who are "now almost compelled to publish in English" (2013: 54). There is definitely an urgent need to explore the growing number of writing voices for whom English has become their default language (Bocanegra-Valle, 2014).

\section{Pragma-dialectics for the systematic analysis of academic discourse}

\subsection{Theoretical Framework}

The writing practices of Spanish scholars are examined from the perspective of argumentation theory and more precisely Pragma-dialectics which places emphasis on the pragmatic dimension of discourse. Pragma-dialectics starts with the assumptions that speakers or writers engage in "a critical discussion" with the purpose of resolving a difference of opinion and delineates an ideal model aimed at facilitating the systematic assessment of argumentation (van Eemeren \& Grootendorst, 2004: 59). Critical discussions presuppose a communicative exchange between at least two participants: a protagonist, the one advancing a position and an antagonist, the one challenging this position. In written communication, as is the case of the scholarly publications, arguers (protagonists) engage in critical discussions with the journal referees (as primary antagonists) and the academic community (general audience) with the purpose of convincing them of the usefulness of their study.

The model of critical discussion indicates four main stages involved in an ideal process of a difference of opinion resolution (van Eemeren \& Grootendorst, 2004: 62). The first is the confrontation stage in which the two parties identify a difference of opinion and advance main claims. The second is the opening stage where the parties establish starting points for the discussion. The third is the argumentation stage where the protagonist defends his/her standpoint by putting forward arguments to counter the antagonist's objections or doubt. Finally, the fourth stage is the concluding stage, where the 
discussion parties evaluate to what extent their initial difference of opinion has been resolved and in whose favor.

Argumentation in real life is far from being ideal. People tend to keep many stages implicit and more importantly they use strategies to maintain the balance between reasonableness and effectiveness. For this reason, the reconstruction of discourse moves is an essential task in Pragma-dialectics (van Eemeren \& Grootendorst, 2004: 96). It allows the analyst to identify the implicit stages that could clarify the different moves, hence determine the kind of argument schemes pursued and detect fallacies. Reconstruction is fundamental for detecting the most important moves, those that show strategic maneuverings.

By strategic maneuvering, Pragma dialectics refers to the "arguer's continual effort to reconcile aiming for effectiveness with being reasonable (van Eemeren, 2010: 12). When arguing, people seek to convince their audience by using sound, logical arguments which are both dialectically acceptable and rhetorically appealing. The ability to convince requires a good command of strategic maneuvering in any communicative setting and mainly in more formal settings. Generally, strategic maneuvering takes place in all the stages of argumentative discourse and manifests itself simultaneously in three levels: 1) the choices that are made from the topical potential available at a particular stage, 2) the adaptation to audience demand, and 3) the use of specific presentational devices. These levels are distinguished for analytic purposes only while they work together in real- life discussions.

Strategic maneuvering at the level of topical choice may be realized by the selection of a specific line of reasoning from topical potentials. For instance, using an argument from authority, such as theorems and rules or citing senior scientists, entails taking a different path from, say, using an inductive argument from example. By topical potential, van Eemeren refers to argumentation scheme, which is "the kind of relationships established between the main claim and the arguments put forward to defend it" (van Eemeren 2010: 98). Argumentation schemes are stereotypical patterns of inference, combining semantic-ontological relations with types of reasoning and logical axioms (Macagno 2015: 192). An argument from cause to effect, for instance, may be represented by different types of inferences; each type has a specific rule of inference and a semantic causal relationship. Hence, by choosing a specific rule, the arguer determines the kind of inference to be drawn and the degree of its validity. As for maneuvering by audience adaptation, arguers most commonly make use of conciliatio. This rhetorical device is recognized when the arguer "uses a proposition the audience is explicitly committed to in order to support his own standpoint" (van Eemeren, 2010: 237). Conciliatio is an efficient strategy to earn the audience's sympathy and influence their position towards the advanced claim.

The evaluation and analysis of strategic maneuvering involves determining the plausibility of the moves and their logical validity. Pragma-dialectics draws upon universally shared rules from argumentation theory and lists them as rules for critical discussion (van Eemeren and Grootendorst 2004: 123). These rules guide people in their production of logically valid reasoning. Strategic maneuvering derails when a rule for critical discussion is violated, producing a fallacious move.

\section{2. Analytic procedures}

Pragma-dialectics, along with its notion of strategic manoeuvring have been used to examine a corpus of 60 abstracts of research articles published by Spanish scholars in international academic journals. The research articles were randomly retrieved from high impact factor (IF) science and engineering journals published in English between 2010 and 2016. The only criterion for their selection was the authors' academic affiliations to a Spanish academic institution while of course having recognized Spanish names. Most articles were authored by at least two scholars, who belonged to 
various technical universities from different regions of Spain. The corpus covered a wide range of academic disciplines. Twenty four abstracts belonged to six disciplines from sciences such as physics and biology. The remaining thirty six abstracts were taken from eleven engineering disciplines, namely, mechanical, thermal and marine, among others. The average length of each abstract was 230 words. After collection and coding, the data were processed following the method of Pragma-dialectics and its analytic tools.

Data processing involved a number of steps. The first was the reconstruction of the argumentative discourse of each abstract and identification of its structure and the four stages corresponding to the model of critical discussion. Along this task, all the discourse moves, namely the claim, the starting points or the supporting arguments were determined. The discourse moves were also characterized against the conventional structure of the abstract as an academic genre (Swales, 1990). The purpose was to determine in which section (background, method, results and conclusion) the main strategies were used. The second step focused on characterizing the moves in terms of their strategic function and in identifying the ones which bore the highest strategic maneuvering in the abstract. These would be the moves which indicate the authors' level of efficiency when getting to achieve the balance between reasonableness and effectiveness.

\section{Findings}

\section{1. Maneuvering in standpoints}

The first set of results obtained from argumentative analysis focused on standpoints, which were the moves the scholars advanced to achieve the aim intended for publication. After categorizing these standpoints, findings indicated that they were unequally distributed within the different abstract sections and revealed a high percentage of standpoints in the method section. As table 1 below indicates, almost $70 \%$ of the claims were explicitly advanced within the sections which define the studies procedures. These moves were chiefly realized through either maneuvering at the topical level or at the rhetorical device level.

Table1. Distribution of standpoints within the abstract sections

\begin{tabular}{lllll}
\hline $\begin{array}{l}\text { Abstract section/ } \\
\text { Maneuvering level }\end{array}$ & Background & Method & Results & Conclusion \\
\hline Topic & 5 & 28.3 & 8.3 & 6.6 \\
Audience & 6.6 & 8.3 & 0 & 3.3 \\
Presentational devices & 1.6 & 31.6 & 0 & 0 \\
\hline Total & 13 & 68.3 & 8.3 & 10
\end{tabular}

Authors maneuvering strategically in the method sections essentially nominalized and reified (verbs turned into nouns) their research processes. Using nominalization, or objectivation, (van Leeuwen, 2008) is characteristic of scientific discourse and it allows concepts to become agents and to shed probably a sense of objectivity on human actions. Scholars in the current sample seem to have captured the essence of the scientific writing conventions in academia which devise agency to concepts, constructs and research processes (Billig 2008; Lemke, 2005). Nominalization seem to have its consequences on argumentation, as arguers objectivize their own actions and embed them as processes. This probably lends more power to methods than to their actors, as they carry the validity of their main 
arguments. In the current corpus however, objectivation is underpinned with maneuvers geared towards effective language as shown in example (1) when the adjective "careful" is used as reinforcement for the action taken by the arguer "treatment".

(1) As the method requires the use of open boundaries, a careful treatment of both inflow and outflow boundary conditions has been carried out.

This recurring strategy in the corpus may be indicative of the arguers' effort to reason effectively. By attempting to add value to their methods through presentational devices the authors probably reveal a certain distance with their audience reflected in the need for assurance and clarification. The overall inclination toward this strategy may be motivated by their concern for the acceptance of their papers.

\section{2. Strategic focus and possible interpretations}

As for the most prominent strategic maneuvers performed in the corpus sample, results revealed a high level of maneuvering both with rhetorical devices and with adaptation to the audience. As illustrated in table 2, most strategic moves were either performed in the opening stage, where common assumptions are recalled, or in the argumentation stage, where the claim is defended. In $25 \%$ of the corpus, arguers draw on common ground, by explicitly referring to shared scientific knowledge such as rules or laws. The strategies may be indicative of the arguers' uncertainty about the amount of common ground needed, and their striver to get their work properly grasped and hence accepted.

Table 2. The major strategic maneuvers

\begin{tabular}{llll}
\hline $\begin{array}{l}\text { Maneuvering level/ } \\
\text { Discussion Stage }\end{array}$ & Topic & Audience & $\begin{array}{l}\text { Presentation } \\
\text { devices }\end{array}$ \\
\hline Confrontation & 1.6 & 3.3 & 1.6 \\
Opening & 3.3 & 25 & 3 \\
Argumentation & 1.6 & 6.6 & 34 \\
Conclusion & 13.3 & 0 & 6.6 \\
\hline Total & 20 & 35 & 45
\end{tabular}

The visible preference for presentational devices to support argumentation in 35\% of the cases is equally significant. Scholars in scientific disciplines typically assign research tools and methods the role of the premises which support their claims. The methods are supposed to be sufficient evidence and are expected to act as starting points and as part of the opening stages. Arguers in our corpus, however, take methods and research tools to the stage of argumentation and debate and show effort in establishing their credibility. Indeed, in many cases the maneuvers centered in using a variety of rhetorical tools while characterizing the research processes or methods. The most frequent devices distinguished were encomium, (a rhetorical tool for praise) and a variety of modifiers. An illustration of such maneuverings may be observed in example (2) below, where the noun modifier "powerful" may indicate the author's aim to add character to his/her research tool.

(2) The development of these tools has been carried out using a powerful software called Lognoter 
The use of encomium here is indeed pursued as an overarching strategy, as the author completes this move with further argumentation praising the software and its capacity through a series of usage declaratives (clarifications) that support the same line of reasoning. These strategies may be considered prevailing signs of the authors' apprehensions and insecurity when addressing a wider and international scientific community. Any interpretation of these motivations, however, remains tentative, as more empirical research is needed to learn better about strategic maneuvering of second language arguers and explore their underlying motives.

\section{Conclusion}

The present paper summarizes the argumentative analysis of scientific research abstracts published in English by Spanish scholars. The study attempts to look at the academic writing of non-native speakers of English using argumentation theory tools. The theory of Pragma-dialectics is employed to determine the kinds of strategic maneuvering these scholars tend to perform. Findings revealed a clear tendency for maneuvering with common assumptions and through the selection of presentational devices. These strategies may point out to the authors' distance from their audience hence the need for proximity through these types of maneuvering. Nevertheless, these interpretations remain incomplete and they should be better worked out if contrasted with the argumentative strategies of scholars whose English is their native language.

\section{References} 800

Billig, M. (2008). The language of critical discourse analysis: the case of nominalization. Discourse and Society, 19(6), 783-

Bhatia, V. K. (2014). Analyzing genre: Language use in professional settings. Routledge.

Bocanegra-Valle, A. (2014). 'English is my default academic language’: Voices from LSP scholars publishing in a multilingual journal. Journal of English for Academic Purposes, 13, 65-77.

Flowerdew, J. (2013). English for research publication purposes. The handbook of English for specific purposes, 301-321.

Hanauer, D. I., \& Englander, K. (2011). Quantifying the burden of writing research articles in a second language: Data from Mexican scientists. Written Communication, 28(4), 403-416.

Hofmann, A. H. (2014). Scientific writing and communication. Oxford University Press.

Hyland, K. (2004). Disciplinary Discourses, Michigan Classics Ed: Social Interactions in Academic Writing. University of Michigan Press.

Hyland, K. (2013). Writing in the university: education, knowledge and reputation. Language Teaching, 46(01), 53-70.

Lemke, J. L. (2005). Textual politics: Discourse and social dynamics. Tylor \& Francis

Macagno, F. (2015). A means-end classification of argumentation schemes. In F.H. van Eemeren and B. Garssen (eds.), Reflections on theoretical issues in argumentation theory (pp. 183-201). Springer International Publishing.

Mercier, H., \& Sperber, D. (2011). Why do humans reason? Arguments for an argumentative theory. Behavioral and brain sciences, 34(02), 57-74.

Swales, J. (1990). Genre analysis: English in Academic and Research Settings. Cambridge University Press.

Van Eemeren, F. H. (2010). Strategic maneuvering in argumentative discourse: Extending the pragma-dialectical theory of argumentation (Vol. 2). John Benjamins Publishing.

Van Eemeren, F. H., \& Grootendorst, R. (2004). A systematic theory of argumentation: The pragma-dialectical approach (Vol.

14). Cambridge University Press.

Van Leeuwen, T. (2008). Discourse and Practice: New tools for critical discourse analysis. Oxford University Press. 